\title{
EL PROCESO ELECTORAL PERUANO
}

\author{
EDGAR CARPIO MARCOS \\ Profesor de Derecho Constitucional \\ Universidad de Lima
}


SUMARIO

I. INTRODUCCIÓN. II. El ORDENAMIENTO ELECTORAL DE LA RE-REELECCIÓN PRESIDENCIAL. III. Convocatoria. IV. Campaña electoral. V. Elecciones presidenciales. a) Primera vuelta; $b$ ) Segunda vuelta. VI. ELECCIONES PARLAMENTARIAS. 


\title{
EL PROCESO ELECTORAL PERUANO
}

\author{
POR \\ EDGAR CARPIO MARCOS \\ Profesor de Derecho Constitucional. \\ Universidad de Lima
}

\section{INTRODUCCIÓN}

El último proceso electoral peruano, el más polémico de los últimos cincuenta años, aunque formalmente se inició el 21 de noviembre de 1999, fecha en la que el Presidente de la República ordenó la publicación en el diario oficial El Peruano del decreto de convocatoria a elecciones empezó a debatirse con mucho tiempo de antelación, cuando el Congreso de la República sancionó la Ley 26657, denominada «Ley de interpretación auténtica del artículo 112 de la Constitución». Por virtud de dicha ley se autorizaba al Presidente de la República, que había sido reelegido en el proceso electoral de 1995, a postular a una nueva re-reelección presidencial, a pesar de que la Constitución de 1993 lo prohíbe.

Aunque aquí no podamos ofrecer los pormenores del debate que desde entonces se ha venido tejiendo, creo sin embargo que es necesario esbozar un breve panorama de lo que aconteció, pues en todos los problemas que durante y después del último proceso electoral se haya podido suscitar, ha estado presente los siempre nocivos efectos que tiene en los países de esta parte del Continente la autorización de la reelección presidencial inmediata.

En todo ello ha contribuido; además, la propia estructura del nuevo sistema electoral creado por la Constitución de 1993. Pues si bien el 
proceso electoral del 2000 era el segundo que se realizaría desde que ella entró en vigencia, en realidad se trataba del primero en su orden y donde se aplicaría el novísimo sistema electoral diseñado, pues las elecciones de 1995 se llevaron a cabo aplicándose una legislación electoral pre-constitucional, ahora modificada.

No se trataba pues, de un proceso electoral más. A la importancia de elegirse a las autoridades políticas más importantes del país dentro de un contexto de ausencia de estabilidad política, se sumaba la evaluación de la eficacia del nuevo sistema electoral, tan criticado durante y después de los debates constituyentes del año 931. Lamentablemente las dudas, críticas y temores que entonces se esbozaron no estuvieron alejados de la realidad, según veremos más adelante.

\section{EL ORDENAMIENTO ELECTORAL DE LA RE-REELECCIÓN PRESIDENCIAL}

Como se sabe, históricamente en la América latina la posibilidad de que un Presidente en ejercicio pueda reelegirse en forma inmediata ha sido un factor de desestabilización del sistema democrático, y por consiguiente un peligro para el régimen de libertades fundamentales².

Su prohibición, en ese sentido, ha estado ligado a la propia viabilidad de la democracia constitucional, y ha sido un freno que se ha impuesto contra los efectos nocivos de una extrapolación defectuosa del régimen presidencial, que ha desencadenado que nuestros países parezcan más monarquías republicanas que regímenes de democracia representativa, cuya diferencia con las del Ancién Régimen, como lo pusiera de relieve Duverger ${ }^{3}$, se encuentra en la designación popular del Presidente y la limitación en el tiempo de su mandato, que en la manera de ejercer el poder estatal.

Por ello es que una tradición constitucional nuestra, que no ha tenido mayores rupturas que las acontecidas durante el gobierno de Augusto $B$. Leguía en la segunda década del siglo $X X$, $y$ en el siglo $X I X$

1 Cfr. Valentín Paniagua Corazao, "Sistema electoral", en La Constitución de 1993. Análisis y comentarios, CAJ, Lima, 1994, pág. 231 y ss.

2 Cfr. últimamente, el valioso trabajo de Mario D. Serrafero, Reelección y sucesión presidencial. Poder y continuidad, Edit. Belgrano, Buenos Aires, 1997, passim.

3 Maurice Duverger, La monarquía republicana, o cómo las democracias eligen a sus reyes, Edit. Dopesa, Barcelona, 1974, passim. 
con la Carta de 1828, ha sido la de prohibir la reelección presidencial inmediata. No obstante ello, y por segunda vez en lo que iba del siglo XX, el constituyente de 1993 volvería a romper con esa tradición, al introducirla en la Constitución de aquel año.

El artículo 112 de la Constitución vigente, en efecto, establece que "El mandato presidencial es de cinco años. El Presidente puede ser reelegido de inmediato para un periodo adicional. Transcurrido otro periodo constitucional, como mínimo, el ex-presidente puede volver a postular, sujeto a las mismas condiciones".

De acuerdo con dicho precepto, el Presidente de la República puede mantenerse en el poder durante 10 años consecutivos, luego de los cuales si existiese la intención de volver a alcanzar la más alta magistratura del Estado, debe dejar transcurrir entre medio al menos un periodo presidencial, esto es, cinco años.

El Presidente en ejercicio, Ingeniero Alberto Fujimori Fujimori, fue elegido por primera vez en el proceso electoral de 1990 para un mandato presidencial de 5 años, encontrándose en vigencia la Constitución de 1979, cuyo artículo 205 establecía que "El mandato presidencial es de cinco años. Para la reelección, debe haber transcurrido un periodo presidencial" (subrayado mío).

Durante la vigencia de dicho mandato, y antes que finalizara el periodo para el que fue elegido, el 5 de abril de 1992, el Presidente Fujimori promovió un "autogolpe" de Estado, que culminó con la disolución del Congreso de la República, la intervención del Poder Judicial, el Ministerio Público, la clausura del Tribunal de Garantias Constitucionales y la de otros órganos constitucionales.

No duró mucho el régimen pretoriano. Como consecuencia de la fuerte presión internacional, algunos meses después, el restablecimiento de la institucionalidad democrática empezaría con la instalación de un Congreso Constituyente Democrático y la expedición de una nueva Constitución, la que entró en vigor el 31 de diciembre de $1993^{4}$.

Al expedirse el nuevo Texto Constitucional, la prohibición de la reelección presidencial inmediata prevista en la Carta del 79 quedó derogada, y el Presidente Fujimori pudo postular a la primera (y única) re-

4 Cfr. Samuel Abad Yupanoul y Carolina Garcés Peralta, «El gobierno de Fujimori antes y después del golpe», en AA.VV., Del golpe de Estado a la nueva Constitución, Lecturas sobre temas constitucionales, n. ${ }^{\circ}$ 9, Lima, 1993, pág. 85 y ss. 
elección inmediata que el nuevo artículo 112 de la Carta del 93 autorizaba. Que el Presidente en ejercicio postulaba a la reelección inmediata en el proceso electoral de 1995, pues se encontraba autorizado por el artículo 112 de la Constitución, fue la tesis sostenida en su momento por el Jurado Nacional de Elecciones, el máximo órgano de justicia electoral de nuestro país, al desestimar una tacha a la inscripción de su candidatura, que reclamaba la aplicación del artículo 205 de la Constitución de 1979.

No obstante ello, y después que el Presidente Fujimori fuera elegido para el período presidencial 1995-2000, el Congreso de la República, de estructura unicameral y compuesta con una mayoría adepta al Jefe de Estado, en agosto de 1996 expedía la Ley N. ${ }^{\circ} 26657$ por virtud del cual "interpretaba auténticamente el artículo 112 de la Constitución". Según su artículo único, "....la reelección a la que se refiere el artículo 112 de la Constitución, está referida y condicionada a los mandatos presidenciales iniciados con posterioridad a la fecha de promulgación del referido texto constitucional. En consecuencia, interprétase auténticamente que en el cómputo no se tienen en cuenta retroactivamente los periodos presidenciales iniciados antes de la vigencia de la Constitución".

Se trataba de una ley inconstitucional, pues no solamente pretendía abrir la posibilidad de que el Presidente en ejercicio se mantenga en el poder hasta por 15 años, cuando la Constitución sólo permite que sea por 10 , sino porque además realizaba una regulación retroactiva de mandatos presidenciales que ya habían culminado con anterioridad a la fecha en que entró en vigencia, entre otros aspectos ${ }^{5}$.

\section{Las primeras instancias de control desvirtuados y la re-reelección presidencial: el referéndum y la Acción de Inconstitucionalidad contra la Ley 26657}

Como era de esperarse, los serios vicios de legitimidad constitucional que la ley de interpretación auténtica anidaba, no tardaría que se impugnase ante diversas instancias de control, tanto de carácter político como jurídico. Ambos sufrirían igual suerte, no por el carácter infundado de sus planteamientos, sino como consecuencia de la manipulación de las instancias de control y de los medios con que cuenta

5 Cfr. AA.VV., Reelección presidencialy derecho de referéndum, Fundación Hanns Seidel, Lima, 1997, passim. 
un Presidente y su mayoría parlamentaria cuando de facto se pretende mantener en el poder.

En setiembre de 1996, se inició una cruzada ciudadana destinada a recopilar firmas para someter a referéndum la Ley 26657, y así obtener su derogación. Un mes después, el Congreso aprobaba la Ley 26670 mediante la que se exigía, como condición para someter a referéndum una ley, contar necesariamente con la aprobación de cuando menos 48 congresistas, de un total de 120 . Se trataba de un número de representantes ante el Congreso que las fuerzas democráticas de oposición no contaban, y que desde luego afectaba el contenido esencial de la institución del referéndum ${ }^{6}$.

Frustrado este mecanismo de participación en la vida política del país, sólo quedaba que la ley 26657 fuese sometida al control concentrado de constitucionalidad con el objeto de expulsarla del ordenamiento jurídico. Sin embargo, y como ya se había observado con anterioridad a propósito de otros temas políticamente sensibles, pocas esperanzas se aguardaban que el Tribunal Constitucional pudiese resolver el problema jurídico-político.

Y asi efectivamente sucedería. La Acción de Inconstitucionalidad contra la referida ley 26670 no prosperaría. El sistema de votación establecido en la Ley Orgánica del Supremo Intérprete de la Constitución, que ha previsto como condición para que el Tribunal expida una sentencia estimatoria, la concurrencia de 6 votos conformes de un total de 7 Magistrados que lo integran, impediría que se resolviera válidamente el asunto.

Contra todas las expectativas, en enero de 1997, el Guardián de la Constitución ordenaba la publicación en el diario oficial EI Peruano de dos "sentencias" sobre la ley de interpretación auténtica. La primera, suscrita por tres Magistrados y con la abstención de otros cuatro, declaraba "por unanimidad" que la Ley 26657 era inaplicable para el caso del Ingeniero Alberto Fujimori Fujimori si éste presentaba su candidatura presidencial en el proceso electoral que tres años después (esto es, en el año 2000) se realizaría. La segunda "sentencia», suscrita por dos Magistrados, declaraba infundada la demanda, y por tanto constitucional la Ley 26657, tras no alcanzarse

6 Pedro Planas, "La lucha por el Estado de Derecho en el Perú (la reelección forzada y el referéndum desvirtuado)", en Anuario de Derecho Constitucional Latinoamericano, Medellín, 1997, pág. 465-470. 
el voto conforme de 6 magistrados de 7 que conforman el Tribunal Constitucional?.

No pudiendo considerarse ninguno de los dos proyectos como "sentencias", pues es obvio que un órgano colegiado no puede expedir a propósito de un caso dos pronunciamientos distintos ${ }^{8}$, la aplicación o no de la Ley 26657 en el proceso electoral del año 2000 tendría que esperar el pronunciamiento definitivo del máximo órgano de la justicia electoral en el Perú (art. 178.4 de la Constitución)9.

\section{El Jurado Nacional de Elecciones y la re-reelección presidencial}

Sin embargo, para que el Jurado Nacional de Elecciones resolviera sobre la aplicación o no de la Ley 26657 debía de esperarse casi tres años, y siempre y cuando el Presidente reelecto en 1995 intentara inscribir su candidatura para un tercer mandato presidencial, que por cierto la Constitución no permitía.

Ya desde entonces, era una muestra de ingenuidad política pensar que el Presidente Fujimori no inscribiría su candidatura en el proceso electoral del 2000. Los acontecimientos previos, que se habian empezado a prever con casi 4 años de anticipación, no hacían dudar de que ello efectivamente sucedería.

Dos serían los momentos en que el Jurado Nacional de Elecciones podría resolver con carácter definitivo si el Presidente en ejercicio, al amparo de la Ley 26657, podía postularse por tercera vez consecutiva. En primer lugar, cuando aquél intentase inscribir su candidatura; en segundo término, cuando tuviese que resolverse las tachas o impugnaciones a la inscripción provisional de la candidatura, que por los antecedentes descritos, no se harían de esperar.

Sin embargo, con el objeto de evitar que la solicitud de inscripción de la candidatura del Presidente pudiera ser vetada por el Jurado

7 Un análisis global, en César LANDA Arrovo, Tribunal Constitucional y Estado Democrático, PUCP, Lima, 1999.

8 Una posición contraria, que asigna valor de "sentencia» al proyecto que declaraba la inaplicabilidad de las Ley 26.657, y que un buen sector de la doctrina nacional por cierto no comparte, puede verse en César LANDA, Tribunal Constitucional y Estado Democrático, citado, pág. 210 y ss.

9 Cfr. Francisco Fernández Segado, «El control normativo de la constitucionalidad en el Perú: crónica de un fracaso anunciado", en Revista Española de Derecho Constitucional, n. ${ }^{\circ}$ 56, CEPC, Madrid, 1999, pág. 11 y ss. 
Nacional de Elecciones, en mayo de 1998 se expidió la Ley 26954 por medio de la cual se modificó el sistema de votación del Jurado Nacional de Elecciones. Ahora, para resolver si se admitía la inscripción provisional de la candidatura presidencial, como a su turno, para resolver las tachas contra la inscripción provisional, se requería contar con 4 votos conformes de los 5 que integran el Jurado Nacional de Elecciones.

El problema, por tanto, se derivaba a la imparcialidad y autonomía que podrían observar los integrantes del Jurado. Teóricamente hablando, la Constitución de 1993 ha previsto una composición técnica del máximo órgano de la justicia electoral, privilegiando el aspecto jurídico sobre el político. No obstante ello, con la finalidad de impedir que el máximo órgano del sistema electoral obstaculizara los afanes rereeleccionistas, se previeron fórmulas legislativas que permitieran al Gobierno contar con un número suficiente de integrantes del Jurado Nacional de Elecciones como para neutralizar su papel de garante de la legalidad del proceso electoral.

La intervención del Poder Judicial y el Ministerio Público, dispuesta desde el autogolpe de 1992 y con la finalidad de desarticular cualquier forma de control sobre el poder, desde 1996 se utilizó también para la re-reelección presidencial, pues sucede que de los 5 integrantes con los que se encuentra integrado el Jurado, dichos órganos constitucionales designan a dos integrantes.

Con tal propósito, se dispuso legislativamente que la elección de sus representantes se llevara a cabo tanto entre los (pocos) magistrados titulares que habían sorteado el "autogolpe" del 92, como entre los magistrados provisionales, éstos últimos cuyo nombramiento se lo debían al Gobierno.

A ello, había que sumar la promulgación de una intencionalmente defectuosa normatividad electoral. En efecto, el Congreso de la República, que antes había aprobado la ley de interpretación auténtica, al expedir la Ley Orgánica de Elecciones (1997) no había previsto entre las causas para tachar la inscripción de una candidatura presidencial (art. 110) el supuesto de infracción al artículo 112 de la Constitución. De hecho se trataba de una laguna (sospechosa, por lo demás) que, de contarse con un Jurado Electoral autónomo, no habría significado ningún problema, pues es evidente que entre el vacío legislativo de la regulación electoral y el artículo 112 de la Constitución, al Jurado le correspondía aplicar directamente la Constitución, que también es una norma jurídica, aunque no cualquier clase de norma, sino precisamente la norma suprema. 
Como era de esperarse, no contándose con un Jurado Nacional de Elecciones que pudiera realizar su labor de manera imparcial, habiéndose previsto un sistema de votación irrazonable y no contándose con una adecuada legislación electoral; el Jurado Nacional de Elecciones admitió la inscripción provisional de la candidatura del Presidente en ejercicio (Resolución 2144-99-JNE); y frente a las tachas, impugnaciones y solicitudes de nulidad que se plantearon, no dudaría en desestimarlas (Resolución 2199-99-JNE), por considerar, unánimemente, que no encontrándose entre los supuestos de procedencia de la tacha la infracción del artículo 112 de la Constitución, éstas eran improcedentes ${ }^{10}$.

De esa forma, el Jurado Nacional de Elecciones, el último bastión de la transparencia del proceso electoral del 2000 y en el que desde 1997 se había depositado la fe en la constitucionalidad del proceso, abdicaba de su función. De ahora en adelante, agotados todos los mecanismos pre-electorales por detener el avasallamiento de la legalidad constitucional, la última palabra la tendría el electorado.

\section{CONVOCATORIA Y CANDIDATURAS ELECTORALES}

De acuerdo con el artículo 118. 5 de la Constitución de 1993, el órgano constitucional encargado de convocar a elecciones generales es el Presidente de la República. Tanto las elecciones presidenciales como las legislativas, de conformidad con la Ley Orgánica de Elecciones (Ley 26859), se realizan cada cinco años y en forma conjunta, el segundo domingo del mes de abril (arts. 16 y 20 ).

En ejercicio de dicha atribución constitucional, con fecha 21 de noviembre de 1999, el Presidente de la República ordenó la publicación del Decreto Supremo N. ${ }^{\circ}$ 040-99-PCM en el diario oficial El Peruano, mediante el cual se convocaba a elecciones generales para el 9 de abril del 2000.

El artículo 109 de la misma Ley Orgánica de Elecciones establece que la inscripción de las candidaturas para los cargos de Presidente y Vicepresidentes de la República, se pueden realizar hasta 90 días naturales antes de la fecha programada para las elecciones.

10 Para un análisis de la actuación del Jurado Nacional de Elecciones, puede verse los diversos trabajos contenidos en el número especial de "Diálogo con la jurisprudencia», n. ${ }^{\circ} 16$, Gaceta Jurídica, Lima (enero) 2000, especialmente en págs. $17-82$. 
La misma Ley Orgánica establece que la lista de candidatos de los movimientos que se inscriben para participar en las elecciones presidenciales, debe contener necesariamente un candidato a la Presidencia de la República y dos candidatos para las dos vicepresidencias.

Dentro de dicho plazo, que culminaba el 27 de diciembre de 1999, se inscribieron 9 movimientos políticos: Partido Acción Popular, Frente Popular Agrícola del Perú, Avancemos, Partido Aprista Peruano, Unión por el Perú, Alianza Electoral Perú 2000, Movimiento Solidaridad Nacional, Movimiento Político Somos Perú y Movimiento Perú Posible.

Sin duda, el hecho más trascendental, que motivó un duro y apasionado debate, ocurrió con la admisión de la inscripción de la candidatura a la Presidencia de la República del Ingeniero Alberto Fujimori Fujimori. Como ya se ha expuesto, el Jurado Nacional de Elecciones no observó mayores problemas en admitir aquella candidatura, y de ese modo tiñó de vicios de inconstitucionalidad lo que quedaba del proceso electoral.

Aunque desde algunos sectores opositores al régimen, se barajó la posibilidad de retirar las candidaturas presidenciales de oposición, al final su desarticulación y la presencia de algunos intereses individuales, terminaron por frustar un retiro conjunto. Por cierto, el mantenimiento de las diversas candidaturas y la participación en la campaña electoral de los diversos grupos de oposición, en nada alteraban la crisis de legitimidad constitucional del proceso electoral, pues según se sabe la Constitución no es una norma cuya validez pueda depender de lo que hagan o dejen de hacer los actores políticos.

Lo que no se imaginaban los diversos partidos y movimientos de oposición, es que no solamente tendrían que competir contra un candidato inconstitucionalmente admitido en el proceso electoral, sino también en un proceso en el que no se les permitiría hacer conocer sus propuestas y ofertas políticas a los electores, como veremos luego.

Ya inscrito el Presidente candidato a la re-reelección presidencial, uno de los diarios más serios e importantes del país, El Comercio, denunciaba que en el proceso de recolección de firmas para inscribir a la Alianza Perú 2000, se habían falsificado indiscriminadamente miles de firmas de adhesión. Tales denuncias, aún a la fecha, y no obstante que el proceso electoral culminó hace algunos meses, no han sido esclarecidas.

En lo que a las elecciones parlamentarias se refiere, como ya se ha anticipado, se llevarían simultáneamente con las presidenciales, se 
inscribieron aparte de las agrupaciones políticas que lo habian hecho con sus candidatos para la Presidencia de la República, el Frente Independiente Moralizador. A diferencia de lo que sucede para la elección presidencial, el plazo para la inscripción de la lista de candidatos al Congreso de la República es de 60 días naturales anteriores a la fecha de realización de las elecciones.

Tales listas, entre las disposiciones más relevantes, no pueden registrar como candidato a quien postula para el cargo de Presidente de la República, si bien no existe ningún impedimento para el caso de los candidatos a las 2 vicepresidencias. Además, el artículo 116 de la Ley Orgánica Electoral dispone que tales listas, compuestas de 120 candidatos al Congreso, deben incluir un número no menor del $25 \%$ de mujeres o de varones.

\section{CAMPAÑA ELECTORAL}

Un elemento capital de todo proceso electoral está constituido por la campaña electoral, pues precisamente en el interregno de ella, las agrupaciones que participan en la lid democrática comunican al electorado sus programas e ideas con el fin de captar el mayor número de votos.

Una elección sin campaña electoral, o con una campaña mediatizada, no sólo atenta contra la posibilidad de que los participantes en los procesos electorales conozcan directamente las propuestas, programas e ideas de las agrupaciones políticas en lid, sino además desnaturaliza el contenido esencial de las elecciones democráticas, pues impide que el electorado pueda elegir libremente entre las diversas opciones políticas y programáticas que se le presentan. Como ha puesto de relieve Solazabal Echevarría, una "campaña constitucionalmente adecuada será... aquella que posibilite unas elecciones libres y competitivas, realizadas en términos de auténtica concurrencia". Y sólo puede considerarse como elecciones competitivas "aquellas celebradas en condiciones de igualdad institucional entre los concurrentes, esto es, sin ventajas o privilegios institucionales para nadie" 11 .

11 Juan José Solazábal Echevarría, "Una visión institucional del proceso electoral", en Revista Española de Derecho Constitucional, n. ${ }^{\circ} 39$, Madrid, 1993, págs. 75 y 67 , respectivamente. 
En el caso de Perú, puede decirse que la campaña electoral fue enormemente restringida para las agrupaciones políticas distintas a la que pertenecía el candidato a una re-reelección presidencial, lo que a parte de los problemas que ya se han descrito, contribuyó aún más en deslegitimar los últimos comicios.

Aunque diversos han sido los problemas que se han podido observar, y que han motivado serias objecciones de los organismos nacionales e internacionales de observación electoral, una apretada síntesis de las principales pueden básicamente esquematizarse así:

\section{Discriminación en el acceso a los medios de comunicación social}

En la realización de los procesos electorales, la utilización de los medios de comunicación social, especialmente los relativos a la radio, prensa y televisión, han devenido en vehículos privilegiados a través de los cuales los movimientos que participan en la lid democrática hacen conocer al electorado sus propuestas.

En el caso de las últimas elecciones generales, el acceso a ellos fue prácticamente impedido a los movimientos políticos de oposición. Así, pudo apreciarse que los canales de televisión de señal abierta, y la que está al alcance del grueso de la población, negaron sistemáticamente el acceso de los movimientos opositores al régimen hasta pocas semanas antes del 9 de abril. A diferencia de procesos electorales realizados con anterioridad, donde pudo apreciarse en general un excesivo uso de éstos, en los comicios del 2000 el único candidato que contó con cobertura de los canales de televisión abierta fue el Presidente Fujimori.

Se trataba de una actitud insólita en nuestra historia electoral, que sólo en parte pudo ser superada más adelante, ante las diversas denuncias que se hicieron, y con pocas semanas al 9 de abril ${ }^{12}$.

Por cierto, muchas son las razones que se han tejido para explicar esta conducta de los medios de comunicación: utilización del aparato fiscal del Estado, presión con la publicidad estatal, y amenazas de utilización del aparato judicial contra los propietarios mayoritarios de los canales de televisión, entre otros. Ciertamente, la explicación oficial que se ha dado ha tratado de ocultar esta realidad, y se ha pretendido

12 Cfr. Defensoría del Pueblo, Elecciones 2000. Informe de supervisión de la Defensoría del Pueblo, Lima (mayo) 2000, especialmente pág. 52 y ss. 
justificar apelando a las instituciones del modelo autoritario de la empresa y la lógica desigualitaria del mercado.

Desde luego, las consecuencias de esta obstaculización en el acceso, impidió que el proceso electoral tuviera un nivel de competitividad mínimo y en iguales circunstancias, a todos los actores políticos. Como se ha señalado, tal situación, en parte pudo enmendarse cuando, faltando escasas semanas para la realización de la primera vuelta electoral, los medios de comunicación suscribieron un acuerdo que tenía por objeto permitir el acceso a los grupos de oposición a los medios de prensa. Sin embargo, los efectos causados ya no eran posibles de ser remediados.

Además, dicho acuerdo no se materializó necesariamente en un acceso a los medios de comunicación en términos igualitarios, pues pudo observarse un tratamiento privilegiado a favor de la alianza política del Presidente candidato. En una medición hecha por una de las organizaciones no gubernamentales que tenía la calidad de observador electoral, la Asociación Civil Transparencia, se constató que faltando escasas semanas para el día señalado para la realización del sufragio, el candidato Fujimori acaparó el $68 \%$ del tiempo televisivo asignado a los candidatos, mientras que el $32 \%$ restante lo fue para el resto de candidatos opositores. Antes del mes de marzo del 2000, en que se realizó tal medición, el porcentaje de cobertura televisiva para el candidato presidente era aún más elevado.

El único medio a través del cual los candidatos de oposición pudieron hacer conocer sus propuestas, fue mediante algunos canales de televisión cerrada (cable), cuyo costo elevado sin embargo impide que el grueso de la población pudiera acceder.

\section{Ataque de los medios de comunicación a los candidatos de oposición}

Asimismo, pudo constatarse que un buen número de medios de comunicación social de carácter escrito, adictos a la candidatura de la re-reelección presidencial, mantuvieron una campaña hostil contra los candidatos de oposición, ataques que se dirigían en función del nivel de aceptación que a lo largo de la campaña (y aún antes) habían logrado, y que se conocía en función de los avances de encuestas que se realizaban.

Con bastante tiempo de antelación, esto pudo observarse con el candidato del movimiento Somos Perú, Alberto Andrade, quien a pe- 
sar de encontrarse en un segundo lugar dentro de las preferencias electorales, finalmente culminó con poco más del $2 \%$ de los votos. Otro tanto sucedió con el candidato presidencial de Solidaridad Nacional, Luis Castañeda Lossio, quien fue sometido a una dura campaña de hostigamiento, inclusive con miembros del Servicio de Inteligencia $\mathrm{Na}$ cional, apenas unos meses antes a la realización del proceso electoral.

Tampoco se escapó de esta campaña, el candidato del movimiento Perú Posible, Alejandro Toledo, que en las últimas semanas previas a la realización de la primera vuelta se colocó en un segundo lugar de los sondeos de opinión, y como consecuencia de ello, fue objeto de duros ataques por cierta prensa escrita y televisada, la que se incrementó notoriamente para la segunda vuelta, después de que se conociera que constituía el más cercano competidor del Presidente Fujimori.

\section{3) Utilización del aparato estatal en favor del Presidente candidato}

Uno de los problemas que enfrenta un régimen que promueve la reelección presidencial inmediata, es que el afán por mantenerse en el poder propicia que la infraestructura estatal pueda ser utilizada para favorecer los intereses del partido en el gobierno. Este problema ya se había podido advertir durante el proceso electoral de 1995, donde abundaron denuncias sobre el uso de bienes e infraestructura estatal en la campaña electoral con el objeto de favorecer a la Alianza Política gobernante. La legislación dictada con la finalidad de impedir tales anomalías, como era de esperarse, tuvo poca eficacia.

En la campaña del año 2000 , se volvió a observar toda ausencia de pudor en la utilización de los bienes estatales para favorecer al candidato a la re-reelección presidencial. Ello se materializó, en primer lugar, con los medios de comunicación social que mantiene el Estado, como es el caso del diario oficial El Peruano y Radio Televisión Nacional (RTN), éste último que trasmitía en directo y en forma completa los mensajes, mítines y otras proclamas de carácter electoral del Presidente en ejercicio, sin observarse un tratamiento semejante con los candidatos de oposición.

Asimismo, se han documentado denuncias sobre utilización de los programas de ayuda social del gobierno para presionar a los sectores menos favorecidos de la población. La Defensoría del Pueblo ha registrado denuncias sobre la participación de trabajadores estatales en la campaña electoral de algunos candidatos al Congreso, ejerciendo funciones públicas o utilizando bienes y recursos de propiedad estatal. 
Al mismo tiempo, ciertos medios de comunicación de carácter escrito denunciaron la utilización de ciertas instalaciones militares para actos de proselitismo político.

De hecho, tales problemas en la campaña fueron aspectos que pudieron presentarse tanto en la primera vuelta como en la segunda.

\section{ELECCIONES PRESIDENCIALES}

De acuerdo con la Constitución de 1993, el Presidente de la República se elige por sufragio directo entre los candidatos que obtienen más de la mitad de los votos, en cuyo cómputo no ingresan los votos viciados ni los votos en blanco (art. 111). El mismo precepto constitucional establece que si ninguno de los candidatos lograra obtener la mayoría absoluta, se procede a una segunda elección, dentro de los treinta días siguientes a la proclamación de los cómputos oficiales, y entre los candidatos que hubieran obtenido las dos más altas mayorías relativas ${ }^{13}$.

Como ya se ha dicho, la votación se fijó para el 9 de abril del 2000. Dicho acto electoral se llevaría adelante entre las 8 meridiano hasta las 4 pasado meridiano. Para tal efecto se instalaron 3,651 centros de votación a nivel nacional, que albergarían un total de 87,277 de mesas de sufragio.

\section{Primera vuelta electoral}

El proceso electoral, con algunos problemas en determinados centros de votación y mesas de sufragio, empezó a las 8 am., como estaba previsto, y se prolongó hasta las $4 \mathrm{pm}$.

Si bien en todo proceso electoral se ha registrado la existencia de determinados problemas, como puede ser el caso de la presencia de propaganda electoral en los centros de votación, realización de manifestaciones políticas, irregularidades en el desempeño de los miembros de mesa, etc, también pudo constatarse otro tipo de deficiencias que ya habían sido advertidas con antelación, como es el caso de pro-

13 Cfr. Francisco Fernández Segado, "El régimen jurídico electoral del Perú», en su libro compilativo Estudios de Derecho Electoral, Ediciones Jurídicas, Lima, 1997, pág. 759 y ss. 
blemas con las listas de electores, irregularidades en las cédulas de votación, entre los más relevantes.

Formalmente culminado el acto de sufragio, diversos medios de comunicación de carácter televisado, a las $4 \mathrm{pm}$. adelantaron sondeos de intención de voto, que pudieron ser recogidos por diversas empresas encuestadoras a través de lo que se llama uencuestas a boca de urna". Dichas encuestas, que son el resultado de la indagación de la intención de voto entre miles de electores al momento de salir de votar de sus centros de votación, y antes de las 2 de la tarde del 9 de abril, arrojaron diversas aproximaciones, pero que en conjunto otorgaban un margen superior al candidato opositor del movimiento político Perú Posible, Alejandro Toledo, por encima del candidato a la re-reelección presidencial, Alberto Fujimori Fujimori, conforme se puede ver en los siguientes cuadros:

\begin{tabular}{llc}
\hline Partido & Candidato & \% de votos válidos \\
\hline Perú Posible & Alejandro Toledo & 45,2 \\
\hline Perú Posible & Alberto Fujimori & 43,6 \\
\hline
\end{tabular}

Fuente: Apoyo.

\begin{tabular}{llc}
\hline Partido & Candidato & \% de votos válidos \\
\hline Perú Posible & Alejandro Toledo & 46,2 \\
\hline Perú 2000 & Alberto Fujimori & 42.6 \\
\hline
\end{tabular}

Fuente: CPI.

\begin{tabular}{llc}
\hline Partido & Candidato & \% de votos válidos \\
\hline Perú Posible & Alejandro Toledo & 48,5 \\
\hline Perú Posible & Alberto Fujimori & 42,7 \\
\hline
\end{tabular}

Fuente: Datum. 
Esta aproximación del sentido del voto, propagados por ciertos medios de prensa televisivos, y ante el silencio de los más próximos al gobierno, muy pronto permitía imaginar que no obstante la estructura montada por el gobierno para mantenerse en el poder por un quinquenio más, la alternancia era inevitable. Sin embargo, pocas horas después, tales resultados se revertirían, ante la incredulidad y desconfianza del electorado nacional.

En todo ello contribuía los primeros informes oficiales del recuento de sufragios que realizaba deficientemente la Oficina Nacional de Procesos Electorales, donde se anunció que el Presidente candidato venía obteniendo la mayoría simple.

Como era obvio, tal situación no haría esperar que se acusara de la realización de un fraude electoral. En cierta forma, tal sospecha se matizó cuando en la noche del 9 de abril, la Asociación Civil Transparencia entregó a los diversos candidatos el resultado del recuento rápido realizado en 739 mesas de sufragio, donde contó con personeros propios, cuyos resultados coincidían en lo sustancial, con el escrutinio de votos realizado por la Oficina Nacional de Procesos Electorales, como se puede ver en el siguiente cuadro:

\begin{tabular}{llc}
\hline Partido & Candidato & \% de votos válidos \\
\hline Perú Posible & Alejandro Toledo & 41,04 \\
\hline Perú Posible & Alberto Fujimori & 48,73 \\
\hline
\end{tabular}

Fuente: Transparencia.

No obstante, la situación de incredulidad frente a lo que venía observándose se acrecentaba con el deficiente accionar de la ONPE, y la entrega de los resultados parciales a cuenta gotas: Uno de los primeros informes, de la tarde del 10 de abril, informaba oficialmente los siguientes resultados, entre los candidatos que habían obtenido las dos primeras mayorías:

\begin{tabular}{llc}
\hline Partido & Candidato & \% de votos válidos \\
\hline Perú Posible & Alejandro Toledo & 39,98 \\
\hline Perú 2000 & Alberto Fujimori & 49,88 \\
\hline
\end{tabular}

Fuente: ONPE, al 39,15\% de las mesas electorales (10 de abril). 
Estos primeros resultados, si bien después del recuento realizado por Transparencia, y que había trascendido a la opinión pública, hacían prever que el candidato con más votos en la primera vuelta era el Presidente Fujimori, sin embargo, no eran suficientes como para que la Oficina Nacional de Procesos Electorales lo proclamara como ganador del proceso electoral, ya que no alcanzaba más de la mitad de los votos válidamente emitidos, como exige la Constitución.

Pero los resultados oficiales que se propagaban no ayudaban a determinar si habría o no una segunda vuelta electoral. En lo que sigue se ofrecen cuadros estadísticos donde se muestran avances de los resultados parciales del proceso electoral, siempre entre los primeros dos candidatos más votados y en distintas fechas:

\begin{tabular}{llc}
\hline Partido & Candidato & \% de votos válidos \\
\hline Perú Posible & Alejandro Toledo & 40,62 \\
\hline Perú 2000 & Alberto Fujimori & 49,63 \\
\hline
\end{tabular}

Fuente: ONPE, basado en el conteo del 55,94\% de las mesas electorales $(10$ de abril).

\begin{tabular}{llc}
\hline Partido & Candidato & \% de votos válidos \\
\hline Perú Posible & Alejandro Toledo & 40,41 \\
\hline Perú 2000 & Alberto Fujimori & 49,85 \\
\hline
\end{tabular}

Fuente: ONPE, basado en el conteo del $77,83 \%$ de las mesas electorales 111 de abrill.

\begin{tabular}{llc}
\hline Partido & Candidato & \% de votos válidos \\
\hline Perú Posible & Alejandro Toledo & 40.31 \\
\hline Perú 2000 & Alberto Fujimori & 49.84 \\
\hline
\end{tabular}

Fuente: ONPE, basado en el conteo del 97,68\% de las mesas electorales $(12$ de abrill.

\begin{tabular}{llc}
\hline Partido & Candidato & \% de votos válidos \\
\hline Perú Posible & Alejandro Toledo & 40,15 \\
\hline Perú 2000 & Alberto Fujimori & 49,89 \\
\hline
\end{tabular}

Fuente: ONPE, basado en el conteo del 99,972\% de las mesas electorales (19 de abril). 
Tal incertidumbre, y la existencia de un mínimo porcentaje para proclamar al Presidente Fujimori ganador en primera vuelta, u optarse por convocar a una segunda vuelta entre los candidatos Fujimori y Toledo, se interpretó que era consecuencia de la manipulación con que venían ofreciéndose el recuento parcial de votos por el ente oficial encargado de realizar los escrutinios. Una manipulación de los resultados oficiales que tenía por finalidad, a juicio de algunos, de examinar cuál sería la reacción de la comunidad internacional, si es que se evitaba (sic) la segunda vuelta.

Finalmente, luego de 21 días de haber concluido el proceso electoral, el 30 de abril, la Oficina Nacional de Procesos Electorales daba a conocer los resultados generales, al 100\%, de las votaciones efectuadas el 9 de abril:

\begin{tabular}{lccc}
\hline Partido & Resultado & $\begin{array}{c}\text { \% de votos } \\
\text { emitidos }\end{array}$ & $\begin{array}{c}\% \text { de votos } \\
\text { válidos }\end{array}$ \\
\hline Acción Popular & 46.509 & 0,39 & 0,42 \\
\hline FREFAP & 80.099 & 0,66 & 0,72 \\
\hline Avacemos & 246.781 & 2,05 & 2,23 \\
\hline Apra & 152.519 & 1,26 & 1,38 \\
\hline UPP & 36.541 & 0,30 & 0,33 \\
\hline Perú 2000 & 5.528 .394 & 45,82 & 49,87 \\
\hline Solidaridad Nacional & 199.813 & 1,66 & 1,80 \\
\hline Somos Perú & 333.049 & 2,76 & 3,00 \\
\hline Perú Posible & 4.460 .812 & 36,97 & 40,24 \\
\hline
\end{tabular}

Fuente: ONPE, al 100\% del conteo de votos (30 de abril).

\section{La segunda vuelta}

Dado que ninguno de los candidatos a la Presidencia de la República obtuvo más de la mitad de los votos válidamente emitidos, se programó la realización de una segunda vuelta electoral. Sin embargo, con la finalidad de evitar los problemas de legitimidad de la primera vuelta, se planteó la necesidad de realizar reformas sustanciales tanto en relación con lo acontecido durante la campaña electoral, como con el sistema de cómputo utilizado por la Oficina Nacional de Procesos Electorales. 
Entre las exigencias más destacadas, cabe mencionar las siguientes:

a) Acceso equitativo a los medios de comunicación social, que permita un trato igualitario a los dos candidatos. Dicho acceso no sólo debería de observarse con los medios de comunicación de propiedad estatal, sino también con los de carácter privado. Esta última exigencia no suponía que se afectara la libertad contractual de estos medios privados, pues únicamente se exigía el respeto de la legislación que regula las telecomunicaciones en el Perú, y especialmente del artículo 8 del Reglamento General de la Ley de Telecomunicaciones, que dispone que «El acceso a la utilización y prestación de los servicios de telecomunicaciones está sujeto al principio de no discriminación; por lo tanto, las empresas prestadoras de dichos servicios, de acuerdo a la oferta disponible, no pueden negar el servicio a ninguna persona natural o jurídica que cumpla las condiciones establecidas para dicho servicio".

b) La postergación de la segunda vuelta electoral para la quincena del mes de junio, y no como se programaría después, para el 28 de mayo.

c) Reformas sustanciales al sistema de cómputo empleado por la Oficina Nacional de Procesos Electorales (ONPE), de modo tal que se garantice la transparencia del escrutinio de votos. Para ello, se exigía que la ONPE proporcionase información sobre la lista de usuarios locales y remotos, autorizados oficialmente para operar con el sistema computerizado; la lista de personas autorizadas a ingresar al centro de cómputo; la lista de direcciones IP's con derecho a conectarse en la red; el acceso, sólo de lectura, al sistema por medio de un terminal para el monitoreo de los archivos "logs", tablas de administración del sistema, medios de trasmisión, información y acceso al sistema de seguridad de la red (firewall), etc.

d) No utilización de los bienes estatales en beneficio del Presidente-candidato; $y$,

e) Compromiso de limpieza en la campaña electoral, a través de un Código de Conducta que promueva un comportamiento ético por parte de ambas fuerzas políticas contendientes.

No obstante el requerimiento de estas condiciones mínimas para la realización de una segunda vuelta, formuladas tanto por los grupos de observadores electorales, nacionales y extranjeros, como por el candidato que obtuvo la segunda mayoría relativa, lo cierto del caso es que no había intención política de dotar al proceso electoral de legitimidad y credibilidad. 
Una de las primeras exigencias, la postergación de la fecha de la segunda vuelta electoral, no fue aceptada por el Presidente candidato. Tampoco lo fue por el Jurado Nacional de Elecciones, pues mediante Resolución N. ${ }^{\circ}$ 570-2000-JNE fijó como fecha para los comicios el 28 de mayo del 2000.

La negativa a suspender la realización de la segunda vuelta electoral, y la persistencia de los problemas de la primera vuelta, ocasionaron que el candidato con la segunda mayoría relativa, el economista Alejandro Toledo, expresara su decisión de "no participar" en la justa electoral. No había en tal decisión una renuncia a su candidatura, y por tanto tampoco cabía la posibilidad de anular la segunda vuelta, y proclamar como Presidente electo al ganador de la primera vuelta con mayoría simple. Se trataba de un medio de presión último al que se había visto obligado a hacer uso, dada la falta de garantías.

Por lo que se refiere a los problemas en el sistema de cómputo de votos, si bien se conformó un grupo de trabajo conformado por representantes de las dos organizaciones políticas que participaban en la segunda vuelta, con representantes de la Defensoría del Pueblo y la Misión de Observación Electoral de la Organización de Estados Americanos, al final las recomendaciones técnicas no fueron tomadas en cuenta.

Más aún, la Oficina Nacional de Procesos Electorales pretendió sorprender a través de un comunicado oficial que el sistema de cómputo se encontraba en óptimas condiciones para asegurar la transparencia del voto, y que ello había sido constatado por el grupo de observación enviado por la OEA. Estos hechos, que fueron desmentidos, y la persistencia en no implementar las medidas técnicas correctivas, así como no permitir la fiscalización del escrutino de los votos a los grupos observadores, finalmente desencadenó que todos los grupos de observación electoral decidieran no participar en la segunda vuelta electoral.

Con todos estos antecedentes ${ }^{14}$, sin candidato de oposición que participara, sin observadores nacionales e internacionales, el 28 de mayo finalmente se llevó adelante los comicios. Los resultados oficiales dados a conocer, fueron los siguientes:

14 Cfr. el informe pormenorizado de la Defensoria del Pueblo, Elecciones 2000. Supervisión de la Defensoría del Pueblo, Lima, julio 2000, especialmente pág. 99 y ss., que es una versión final de todo el proceso electoral. 
ELECCIONES PRESIDENCIALES (SEGUNDA VUELTA)

\begin{tabular}{lccc}
\hline Partido & Resultado & $\begin{array}{c}\% \text { de votos } \\
\text { emitidos }\end{array}$ & $\begin{array}{c}\% \text { de votos } \\
\text { válidos }\end{array}$ \\
\hline Perú Posible & 2.086 .208 & 17,68 & 25,67 \\
\hline Perú 2000 & 6.041 .774 & 51,20 & 74,33 \\
\hline Votos blancos & 140.773 & 1,19 & 0 \\
\hline Votos nulos & 3.531 .730 & 29,93 & 0 \\
\hline
\end{tabular}

Fuente: Jurado Nacional de Elecciones.

El 3 de junio del 2000, pocos días después de haberse realizado la segunda vuelta electoral, y con la rapidez que no se había observado en la primera vuelta, el Jurado Nacional de Elecciones proclamaba como fórmula ganadora del proceso electoral a la lista de candidatos de la Alianza Electoral Perú 2000, integrada por Alberto Fujimori Fujimori como Presidente de la República, y a los señores Francisco Gregorio Tudela Van Breugel-Douglas y Ricardo Márquez Flores, como Primer y Segundo Vicepresidente de la República, respectivamente.

\section{ELECCIONES PARLAMENTARIAS}

El Congreso de la República es de estructura unicameral, y se encuentra integrado por 120 representantes, quienes son elegidos para un periodo de 5 años (art. 90 de la CP). La elección de los congresistas se realiza transitoriamente mediante Distrito Nacional Único, y de acuerdo con un sistema de representación proporcional, que se obtiene aplicándose el método de la "cifra repartidora", con voto preferencial de carácter opcional.

Ello implica, como es sabido, que el total de votos válidos obtenidos por cada lista se divida sucesivamente entre 120, de manera que los cocientes obtenidos sean colocados en orden decreciente hasta obtener un número de ellos igual al número de representantes a elegir. El cociente que ocupe el último lugar constituirá la "cifra repartidora", que servirá para dividir el total de los votos válidos de cada lista, y de esa manera obtener el número de representantes que corresponde a cada una de ellas. 
Finalmente, se proclama como congresistas a los candidatos que hayan obtenido la mayor votación preferencial en cada lista, y en el caso hipotético de que no exista votación preferencial, se proclamará a los candidatos siguiendo el orden en el que aparecen en la lista inscrita.

Bajo esta regulación, y al coincidir las elecciones parlamentarias con las presidenciales, los problemas que pudieron registrarse en esta última se reprodujeron, a los que se agregaron serias denuncias sobre fraude y manipulación de los resultados electorales, especialmente en el recuento de los votos preferenciales. Entre los más desconcertantes, sólo vamos a mencionar dos:

\section{La adulteración de los votos preferenciales}

Como ya se dijo, en el Perú existe el voto preferencial, que puede opcionalmente ser ejercido al momento de sufragar. Aunque en las pasadas elecciones se habían presentado ciertas reclamaciones derivadas del escrutinio del voto preferencial, en las elecciones parlamentarias del 2000 se presentaron una serie de denuncias sobre adulteración con miras a favorecer a determinados candidatos de diversas listas parlamentarias.

Tales denuncias, en las que se han visto involucrados tanto algunos candidatos como digitadores de la Oficina Nacional de Procesos Electorales, si bien fue de conocimiento público, y originó el cese de los servidores comprometidos, no obstante el tiempo transcurrido aún no han sido esclarecidos.

\section{Impedimento de acceso al Congreso del abogado Heriberto Benítez Rivas}

Sin embargo, el caso más grave de manipulación de votos en las últimas elecciones parlamentarias, fue el que se perpetró contra el movimiento político Somos Perú, liderado por el actual Alcalde de la Municipalidad de Lima, Alberto Andrade Carmona, al que literalmente se le despojó de un escaño parlamentario.

Los hechos son los siguientes: El 18 de abril del 2000, en un avance del escrutinio de los votos para congresistas, el titular de la Oficina Nacional de Procesos Electorales informaba a la opinión pública que los resultados al $99,972 \%$, que corresponden a 88,787 mesas de sufragio, otorgaban al Movimiento Somos Perú 725.452 votos. 
De acuerdo con este avance del cómputo, a dicho movimiento le correspondía, de acuerdo con la cifra repartidora, 9 bancadas parlamentarias. Sin embargo, cuando la misma Oficina Nacional de Procesos Electorales, algunos días después, informaba el avance del escrutino al 99,99\%, esto es, 2 centésimos por encima del informado el 18 de abril, inexplicablemente los votos del Movimiento Somos Perú se habían reducido en poco más de 10,000 votos, como puede verse en el siguiente cuadro.

PORCENTAJE DE AVANCE

\begin{tabular}{lrrrr}
\hline Partido & $99,84 \%$ & $99,89 \%$ & $99,97 \%$ & $99,99 \%$ \\
\hline Acción Popular & 243.713 & 244.530 & 248.206 & 245.113 \\
\hline FREPAP & 216.099 & 216.615 & 217.373 & 216.944 \\
\hline Avancemos & 305.884 & 306.665 & 309.104 & 307.185 \\
\hline Partido Aprista & & & & \\
\hline Peruano & 543.239 & 546.043 & 551.137 & 546.923 \\
\hline Unión por el Perú & 253.034 & 254.169 & 255.989 & 254.542 \\
\hline Perú 20o0 & 4.167 .066 & 4.181 .042 & 4.238 .128 & 4.188 .991 \\
\hline Solidaridad Nacional & 397.927 & 399.511 & 401.538 & 399.975 \\
\hline FIM & 747.390 & 749.854 & 750.939 & 751.384 \\
\hline Somos Perú & 711.656 & 714.023 & 725.452 & 715.384 \\
\hline Perú Posible & 2.296 .397 & 2.304 .505 & 2.338 .626 & 2.308 .635 \\
\hline Votos blancos & 698.300 & 701.945 & 726.116 & 703.200 \\
\hline Votos nulos & 1.121 .747 & 1.182 .446 & 1.169 .923 & 1.296 .505 \\
\hline Impugnados & 4.138 & 2.447 & 4.806 & 18 \\
\hline Votos válidos & 9.882 .405 & 9.916 .957 & 10.036 .492 & 11.934 .740 \\
\hline Votos emitidos & 11.706 .590 & 11.803 .795 & 11.937 .337 & 11.934 .740 \\
\hline
\end{tabular}


¿Cómo explicar esta situación? Según los avances proporcionados en materia de cómputo de votos preferenciales, la novena curul del Movimiento Somos Perú le correspondía ocupar al abogado Heriberto Benítez Rivas, un candidato opositor al gobierno de Alberto Fujimori Fujimori, que ha desempeñado un papel importante en la defensa de los derechos humanos.

Dado que no existen explicaciones objetivas y razonables sobre lo que aconteció finalmente con la curul parlamentaria que debería ocupar el abogado Benítez Rivas; todo indica que la manipulación con el escrutinio de los votos preferenciales tenía por objeto impedir su acceso al Parlamento. Así lo ha considerado la Comisión Interamericana de Derechos Humanos en su "Segundo Informe sobre la situación de los derechos humanos en el Perú", del mes de junio del 2000 (párrafo 66).

Tal despojo ha adquirido mayor credibilidad conforme se desarrollaban los hechos subsiguientes. En efecto, el escaño parlamentario despojado al Movimiento Somos Perú se pasó al movimiento "Solidaridad Nacional», que de esta forma hizo un total de 5 curules.

El candidato por dicho movimiento que se iría de ver favorecido, Eduardo Farah, poco tiempo después anunciaría su renuncia al movimiento político en cuya lista fue elegido, así como su pase a las filas del oficialismo.

El 2 de junio del 2000, casi dos meses después de finalizadas las elecciones parlamentarias, el Jurado Nacional de Elecciones oficializaba los resultados electorales 
ELECCIONES LEGISLATIVAS

\begin{tabular}{lccc}
\hline Partido & Resultados & $\begin{array}{c}\text { \% de votos } \\
\text { emitidos }\end{array}$ & $\begin{array}{c}\text { \% de votos } \\
\text { válidos }\end{array}$ \\
\hline Acción Popular & 245.115 & 2,05 & 2,47 \\
\hline $\begin{array}{l}\text { Frente Popular Agrícola } \\
\text { del Perú }\end{array}$ & 216.953 & 1,82 & 2,18 \\
\hline Avancemos & 307.188 & 2,57 & 3,09 \\
\hline Partido Aprista Peruano & 546.930 & 4,58 & 5,51 \\
\hline Unión por el Perú & 254.582 & 2,13 & 2,56 \\
\hline Perú 2000 & 4.189 .018 & 35,08 & 42,16 \\
\hline Solidaridad Nacional & 399.985 & 3,35 & 4,03 \\
\hline Frente Independiente & 751.323 & 6,29 & 7,56 \\
\hline Moralizador & 715.396 & 5,99 & 7,20 \\
\hline Somos Perú & 2.308 .635 & 19,33 & 23,24 \\
\hline Perú Posible & 703.345 & 5,89 & 0 \\
\hline Votos blancos & 1.304 .340 & 10,92 & 0 \\
\hline Votos nulos & 0 & 0 & 0 \\
\hline Votos impugnados & & & \\
\hline
\end{tabular}

Fuente: Oficina Nacional de Procesos Electorales y Jurado Nacional de Elecciones.

Mediante la Resolución N. 863-2000-JNE, el Jurado hacía oficial la proclamación de los congresistas electos, y la nueva conformación del Parlamento Nacional, que quedaba compuesto así: 
DISTRIBUCIÓN DE ESCAÑOS EN EL CONGRESO

\begin{tabular}{lc}
\hline Partido & Número de escaños \\
\hline Perú 2000 & 52 \\
\hline Frente Independiente Moralizador & 9 \\
\hline Partido Aprista Peruano & 6 \\
\hline Acción Popular & 3 \\
\hline Unión por el Perú & 3 \\
\hline Perú Posible & 29 \\
\hline Somos Perú & 8 \\
\hline Solidaridad Nacional & 5 \\
\hline Avancemos & 3 \\
\hline Frente Popular Agrícola del Perú & 2 \\
\hline
\end{tabular}

Fuente: Oficina Nacional de Procesos Electorales.

Según estos resultados oficiales, la Alianza Política de Perú 2000 no contaría con una mayoría absoluta en el Congreso, como la que había disfrutado en el Congreso Constituyente Democrático entre 19931995, y en el Congreso durante el periodo 1995-2000.

La aparente cohesión de los grupos de oposición democrática, que se pudo observar como consecuencia de los graves problemas registrados en la primera vuelta, hacían prever que la Alianza Política Perú 2000 perdería la dirección del Parlamento Nacional, si es que no concertaba una alianza parlamentaria.

Por ello, entre tanto se aunaban esfuerzos en plantear las condiciones para una segunda vuelta en las elecciones presidenciales, utilizando diversos medios se logró que representantes electos en listas de grupos de oposición se pasaran a las filas del oficialismo.

Actualmente, en medio de denuncias de extorsión y pagos por pasarse a la bancada de la alianza oficialista, se estima que el número de "tránsfugas" han pasado los 15 , lo que ha permitido al movimiento del Presidente re-reelecto contar con una cómoda mayoría ${ }^{15}$.

15 Ya concluido este trabajo, y cuando estaba ad portas de enviarse a la redacción de la Revista de Derecho Político este informe, se han propagado a través 
de un canal de cable imágenes donde consta el preciso momento en que un Congresista, entonces todavía electo, firma su renuncia al partido donde fue elegido, a cambio de quince mil dólares que le son entregados por el asesor del Servicio de Inteligencia Nacional, Vladimiro Montesinos, un personaje seriamente cuestionado, a quien se atribuye la autoria de una serie de hechos de corrupción. Esto ha conmovido los cimientos de nuestro sistema político, cuyas consecuencias son impredecibles de aventurar. 